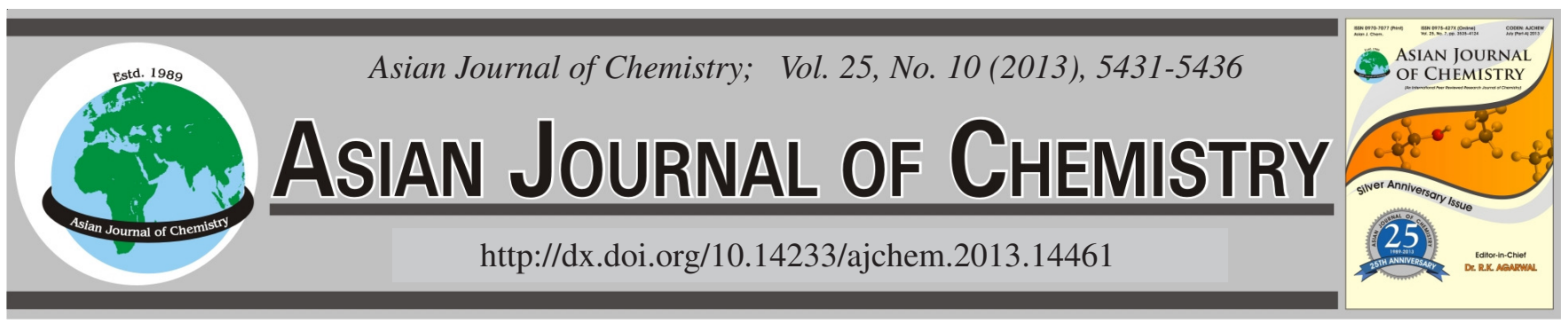

\title{
Effect of Organo Modified Clays Reinforcement on Thermal Expansion and Degradation Kinetics in Unsaturated Polyester Composites
}

\author{
T. Niranjana Prabhu ${ }^{1, *}$, T. Demappa ${ }^{2}$, V. Harish ${ }^{3}$ and Kalappa Prashantha ${ }^{4}$
}

\begin{abstract}
${ }^{1}$ Department of Chemistry, East Point College of Engineering for Women, Bangalore-560 049, India
${ }^{2}$ Department of Studies in Polymer Science, Sir M.V. Postgraduate Centre, Mysore University, Tubinkere, Mandya-571 402, India

${ }^{3}$ Department of Physics, Government First Grade College, Shimoga-577 201, India

${ }^{4}$ Department of Polymers and Composites Technology \& Mechanical Engineering, Ecole des Mines de Douai, 941, rue Charles Bourseul, B.P. 10838-59508 Douai, Cedex, France
\end{abstract}

*Corresponding author: Fax: +91 80 28472999; E-mail: niranjan1975@ gmail.com

(Received: 21 August 2012;

Accepted: 11 April 2013)

AJC-13223

The unsaturated polyester isophthalate (UP) was reinforced with organically modified clay. The composites were analyzed by TGA,
TMA, FT-IR, SEM and UL-94 tests. FT-IR spectra show no reaction between clay and polymer matrix. The thermogravimetric analysis
indicate the increased thermal resistance when clay particles were introduced into the resin. The Horowitz-Metzger, Freeman-Caroll,
Sharp-Wentworth and Friedman kinetic models were used to understand the kinetics of degradation. Degradations were observed to
follow these four kinetic models for polymer degradation. Thermal expansion co-efficient and dimension change were found to decrease
with increase in the clay loading. Further, Underwriters Laboratories -94 tests conducted on the samples implied that materials can be
used for structural applications. UL-94 tests have showed the reduction in burning rate with the increase in clay content. Scanning
electron micrographs reveal good dispersion of the clay particles in the matrix.

Key Words: Unsaturated polyester, Thermal analysis, Thermo-mechanical analysis, Degradation kinetics.

ᄂ _ _ - - - - - - - - - - - - - - - - - - - - - - - - -

\section{INTRODUCTION}

Unsaturated polyester resins are one of the most widely used resins for the fabrication of polymer composites because of their competitive cost and ease of processing ${ }^{1}$. They represent ca. $75 \%$ of the total thermoset composites market. The major advantages of unsaturated polyester resins are a balance of mechanical, chemical, thermal and electrical properties, low cost and ease of handling and processing. With fillers or other additives, unsaturated polyester resins are used in low temperature processes such as resin transfer molding (RTM) and hand lay-up/spray-up, as well as high temperature processes such as compression molding of sheet molding compounds (SMCs) and injection molding of bulk molding compounds $(\mathrm{BMCs})^{2}$. Addition of a small amount of clay to a polymer matrix has been demonstrated to be an effective method to achieve improvements of mechanical, thermal, barrier and chemical properties and flame retardancy ${ }^{3-7}$. The modified organophilic montmorillonite clay reinforced epoxy composites exhibit significant improvements in thermal and mechanical properties like high temperature durability ${ }^{8}$, enhanced barrier properties ${ }^{9}$ and other characteristics. Composites based on polyethylene terephthalate copolymer with organo clays prepared were found to degrade severely with increase in clay content from 0.36 to $7.0 \mathrm{wt} \%{ }^{10}$, whereas organo clay layers when incorporated in polybutylene terephthalate acted as superior insulator and as a mass transport barrier to the volatile products generated during thermal decomposition thus increasing the thermal stability ${ }^{11}$. Dimensional variations with respect to temperature, environmental loads and static loads have to be understood before commissioning polymer composite materials for applications. The thermal expansion coefficient $(\alpha)$ is normally used to describe the dimensional changes of a substance with respect to thermal change. Understanding thermal expansion co-efficient for polymer composite materials is critical in evaluating material ability to withstand thermo-physical variation. Addition of carbon nanofibers is found to increase the glass transition temperature and reduce ' $\alpha$ ' value of unsaturated polyester composites $^{12}$. The observations of Nabeel and Louay ${ }^{13}$ on ' $\alpha$ ' with respect to fiber loading have indicated the decrease in ' $\alpha$ ' with the increasing fiber volume fractions. Hence, in the present work an attempt has been made to understand of thermal expansion and degradation behaviour in unsaturated polyester iso phthalate resin when organo modified montorillonite clay particles were incorporated. 


\section{EXPERIMENTAL}

As per the supplier's literature the isophthalic resin chosen was basically an unsaturated polyester resin prepared using isophthalic acid $\left\{\mathrm{C}_{6} \mathrm{H}_{4}(\mathrm{COOH})_{2}\right\}$, maleic anhydride $\left\{\mathrm{C}_{4} \mathrm{H}_{2} \mathrm{O}_{3}\right\}$, propylene glycol $\left\{\mathrm{CH}_{3} \mathrm{CHOH}-\mathrm{CH}_{2} \mathrm{OH}\right\}$ and styrene $\left\{\mathrm{C}_{6} \mathrm{H}_{5} \mathrm{CH}-\right.$ $\left.\mathrm{CH}_{2}\right\}$ as raw materials in the molar ratio $0.5,0.5,1.0$ and 1.2, respectively. The first three reactants participate in the formation of linear chains while the styrene acts as a cross linking agent. The unsaturated polyester isophthalate resin (UP) (KPR6600) along with accelerator cobalt octoate (3\%) and catalyst methyl ethyl ketone peroxide (MEKP, $50 \%$ ) were procured from KEMROCK Industries, Vadodara, India. The specific gravity of the resin was 1.1 , Viscosity at $25^{\circ} \mathrm{C}$ was $600 \mathrm{cps}$, acid value was 16 and the volatile matter was $35 \%$ as given by the supplier. The organically modified montorillonite clay, cloisite 30-B was procured from Southern Clay products Inc., USA. The average particle size as given by the supplier was $10 \mu \mathrm{m}$ with a density of $1.98 \mathrm{~g} / \mathrm{cc}$. All the chemicals were used without any modifications.

The UP resin was well mixed using a paste mixer (PDM150, Dae Wha Tech Co., Ltd, Korea) at 1350 rotations per minute and 1000 revolutions per minute for $6 \mathrm{~min}$ with appropriate quantities of clays. Then catalyst $(1 \mathrm{phr})$ and accelerator (1 phr) were added into the mixed UP/Clay system. The system was further mixed thoroughly for $3 \mathrm{~min}$ and the contents were decanted into the Teflon mold with a dimension of $100 \mathrm{~mm}$ dia $\times 3 \mathrm{~mm}$ thickness. The samples were cured at room temperature for $2 \mathrm{~h}$ and post cured at $120^{\circ} \mathrm{C}$ for $6 \mathrm{~h}$.

FTIR spectroscopy: The IR spectra were recorded on a Perkin-Elmer Spectrum 2000 FTIR spectrometer, with $\mathrm{KBr}$ pellets to ascertain the possibility of reaction between clay and monomer.

Thermal properties: Thermo-gravimetric analysis (TGA) was carried out using a TGA Q500 V20.2 Build 27 (TA instruments, USA) in the temperature range between 30 and $800{ }^{\circ} \mathrm{C}$ at a heating rate of $10^{\circ} \mathrm{C} / \mathrm{min}$ in nitrogen atmosphere with a flow rate of $60 \mathrm{~mL} / \mathrm{min}$.

Thermo-mechanical analysis (TMA) was carried out on a sample of $5 \mathrm{~mm}$ thickness $\times 5 \mathrm{~mm}$ diameter circular disc where the samples were obtained by using a plastic tube mould. TMA Q400 V7.4 Build 93 (TA instruments, USA) instrument in the temperature range between 30 and $250{ }^{\circ} \mathrm{C}$ at a heating rate of $5{ }^{\circ} \mathrm{C} / \mathrm{min}$, with a load of $0.02 \mathrm{~N}$ was used for the same. The data obtained from TMA were analyzed for a values and dimensional change using universal analysis 2000, version3.9A software supplied by TA Instruments-Waters LLC.

To check the flame retardant properties Underwriters Laboratories-94 tests were conducted as per the procedure of Under Writers Laboratories, USA.

Morphological properties: The morphology of the prepared composites was examined with a LEICA S440i Scanning Electron Microscope (Leica Cambridge Ltd., UK) with accelerating voltage of $15 \mathrm{kV}$ was used to investigate the gold coated fractured surface of each sample of Izod impact test.

\section{RESULTS AND DISCUSSION}

FTIR spectroscopy: The characteristic IR absorption peaks observed for cured neat UP resin and for the other composite samples is shown in Fig. 1. The strong IR absorption peak due to the $\mathrm{C}=\mathrm{C}$ stretching of aromatic ring occurred at $1606,1603,1606,1602,1603$ and $1602 \mathrm{~cm}^{-1}$ with clay composition $0,1,3,5,10,15 \mathrm{phr}$, respectively. The peaks appeared in the range of $3547-3504 \mathrm{~cm}^{-1}$ indicates the presence of hydroxyl group in UP resin. The peak at $3028 \mathrm{~cm}^{-1}$ represents the aliphatic $\mathrm{C}-\mathrm{H}$ stretching of styrene, which may be due to the unreacted styrene monomer. An asymmetric stretching of methylene occurs in the range of $2934-2927 \mathrm{~cm}^{-1}$. The carbonyl group absorption of the polyester is present in the range from $1727-1724 \mathrm{~cm}^{-1}$. Comparison of all FTIR spectra of UP/clay composites and clay indicate the non-occurrence of reaction between resin and clay. The peak at $538 \mathrm{~cm}^{-1}$ in the cured neat resin (UPC 0) spectrum may be due to the cobalt(II) octoate and this peak appearing with low intensity at low concentrations of clay upto $1 \mathrm{phr}$ and onwards which is missing in other spectra of UP/clay composite samples. The peak of 522 $\mathrm{cm}^{-1}$ is due to clay and is present in the spectra of neat clay, 3 , $5,10,15 \mathrm{phr}$ composite samples, whereas the same is missing in $1 \mathrm{phr}$ composite samples. The disappearance of $538 \mathrm{~cm}^{-1}$ peak may be due to the possible reaction between cobalt (II) octoate and the clay.

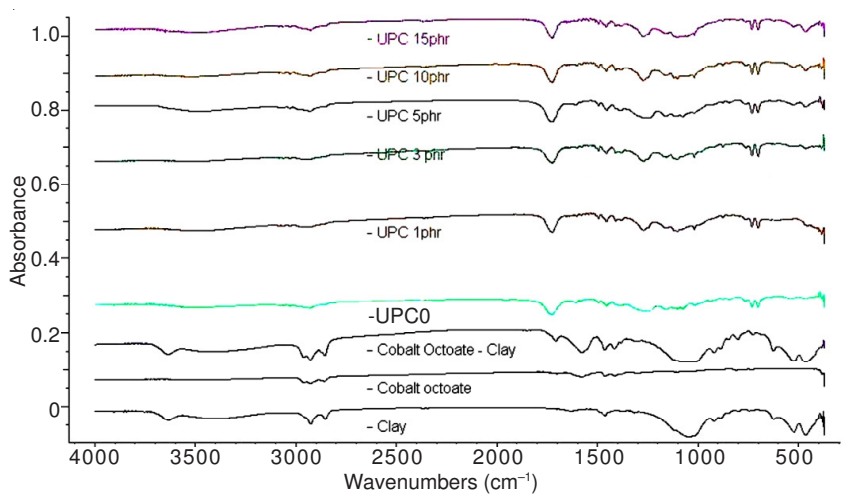

Fig. 1. FTIR spectra of cured neat UP Resin and composite samples of varied clay composition

Thermal properties: The initial degradation temperature (IDT), temperature at maximum rate of degradation $\left(\mathrm{T}_{\max }\right)$, maximum rate of per cent weight loss, $\mathrm{R}_{\max }$ and temperature at $50 \%$ weight loss $\left(\mathrm{T}_{1 / 2}\right)$ of cured neat UP resin and the UP/ clay composite samples are given in Table-1. It is observed that the introduction of clay particles into unsaturated polyester resulted in increase of thermal resistance marginally (Fig. 2 ). This may be due to the binding of clay particles to polymer network, hindering the degradation process.

The Horowitz-Metzger integral kinetic method ${ }^{14}$ was applied to calculate the kinetic parameters. This method can determine the decomposition activation energy with only one heating rate. In this study, the TGA curves at a heating rate of $10{ }^{\circ} \mathrm{C} / \mathrm{min}$ were used to calculate the degradation kinetics for all samples with the following equation:

$$
\ln \left\{\ln \left(\frac{1}{1-\alpha}\right)\right\}=\frac{\mathrm{E}_{\mathrm{a}} \theta}{\mathrm{RT}_{\mathrm{e}}^{2}}
$$

where $E_{a}=$ energy of activation, $\theta=\left(T-T_{e}\right), T=$ temperature at time $\mathrm{t}, \mathrm{T}_{\mathrm{e}}=$ temperature at $\mathrm{W} / \mathrm{W}_{0}=1 / \mathrm{e}, \mathrm{W}_{0}=$ initial weight, $\mathrm{W}=$ weight at time $\mathrm{t}, \mathrm{R}$ is universal gas constant and $\alpha$ is the heating rate. 


\begin{tabular}{lccccccccccc}
\hline \multicolumn{10}{c}{ TABLE-1 } \\
\multicolumn{10}{c}{ RESULTS OF THERMO-GRAVIMETRIC AND THERMO-MECHANICAL } \\
ANALYSIS FOR THE CURED NEAT UP AND UP/CLAY COMPOSITES
\end{tabular}

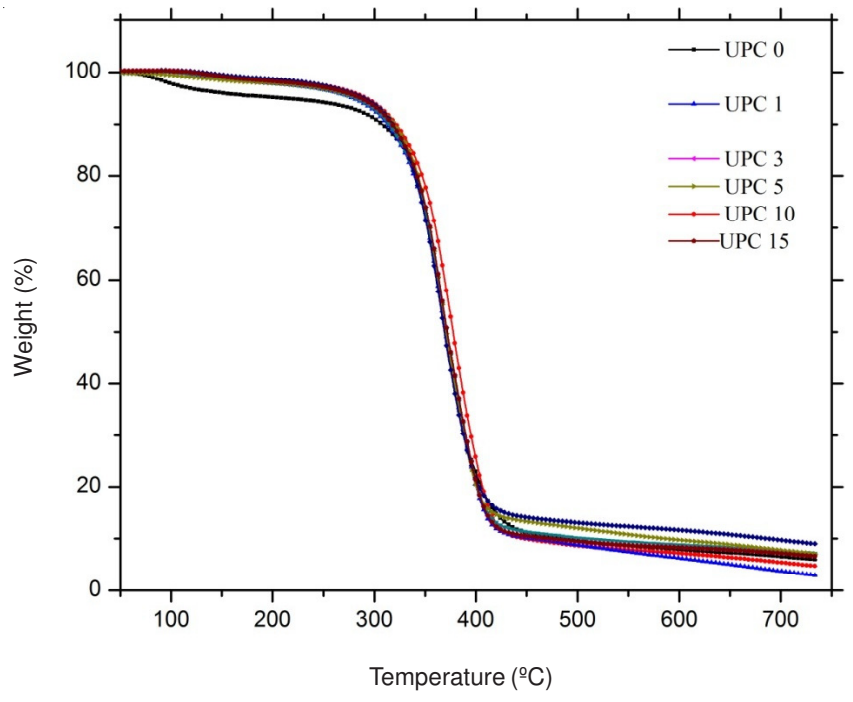

Fig. 2. Thermograms of the neat UP, UP-clay composites

Thus, a plot of $\ln \left\{\ln \left(\frac{1}{1-\alpha}\right)\right\}$ against $\theta$ should give a straight line whose slope gives $\mathrm{E}_{\mathrm{a}}$.

The straight-line equation derived by Freeman and Caroll ${ }^{15}$ is in the form of

$$
\frac{\Delta \log (\mathrm{dw} / \mathrm{dt})}{\Delta \log \mathrm{W}_{\mathrm{r}}}=\mathrm{n}-\frac{\mathrm{E}_{\mathrm{a}}}{2.303 \mathrm{R}} \frac{\Delta(1 / \mathrm{T})}{\Delta \log \mathrm{W}_{\mathrm{r}}}
$$

where $\mathrm{dw} / \mathrm{dt}=$ rate of change of weight with time, $\mathrm{W}_{\mathrm{r}}=$ weight loss at the completion of reaction - total weight loss up to time $\mathrm{t}, \mathrm{E}_{\mathrm{a}}=$ energy of activation, $\mathrm{n}=$ order of reaction, $\mathrm{T}=$ temperature.

The plot between the terms $\frac{\log (\mathrm{dw} / \mathrm{dt})}{\log \mathrm{W}_{\mathrm{r}}}$ versus $\frac{1 / \mathrm{T}}{\log \mathrm{W}_{\mathrm{r}}}$ gives a straight line and slope of which gives the energy of activation $\left(E_{a}\right)$ and intercept on Y-axis as order of reaction (n).

Sharp and Wentworth ${ }^{16}$ derived an equation to explain the degradation kinetics by,

$$
\log \frac{(\mathrm{dC} / \mathrm{dT})}{1-\mathrm{C}}=\log \frac{\mathrm{A}}{\beta}-\frac{\mathrm{E}_{\mathrm{a}}}{2.303 \mathrm{R}} \frac{1}{\mathrm{~T}}
$$

where $\mathrm{dC} / \mathrm{dT}=$ rate of change of fraction of weight with change in temperature, $\beta=$ linear heating rate $\mathrm{dT} / \mathrm{dt}$.

By plotting the graph between $\log \frac{(\mathrm{dC} / \mathrm{dT})}{1-\mathrm{C}}$ versus $1 / \mathrm{T}$, we get the straight line which give energy of activation from its slope and A can be evaluated from intercept.

Friedman ${ }^{17}$ has provided the following expression for thermal degradation kinetic studies based on Arrhenius equation:

$$
\ln \frac{\mathrm{d} \alpha}{\mathrm{dt}}=\ln \mathrm{z}+\mathrm{n} \ln (1-\alpha)-\frac{\mathrm{E}_{\mathrm{a}}}{\mathrm{RT}}
$$

where $\alpha=$ conversion at time $\mathrm{t}, \mathrm{R}=$ gas constant $(8.314 \mathrm{~J} / \mathrm{mol} /$ $\mathrm{K})$ and $\mathrm{T}$ is the absolute temperature $(\mathrm{K})$.

The plot of $\ln (\mathrm{d} \alpha / \mathrm{dt})$ versus $1 / \mathrm{T}$ should be linear with the slope $E_{a} / R$, from which $E_{a}$ can be obtained. From the slope of the linear plot of $\ln (1-\alpha)$ versus $1 / \mathrm{T}, \mathrm{n}$ can be obtained.

For all the four kinetic methods the calculations have been done in the temperature range of $325-352{ }^{\circ} \mathrm{C}$ where major degradation has occurred linearly.

Thermal stability with respect to the thermal resistance at maximum rate of degradation and activation energy has shown an increase for the samples reinforced with clay particles. To compare the degradation behaviours, Table- 1 also lists the derivative peak rate of decomposition of the samples along with other thermal degradation properties. Considering the thermal degradation parameters observed for these samples, it is understood that the reinforcement of clay particles has marginally increased $\mathrm{T}_{\max }$ to an extent of clay composition.

The maximum rate of degradation $\mathrm{R}_{\max }$ has decreased and the activation energy $\left(E_{a}\right)$ has marginally increased with the increase in clay content. But the initial degradation temperature has not shown any improvement with the increase in clay content. The reason may be due to that the clay added might only help to retard the maximum rate of degradation of the matrix. The increase in activation energy with increase in clay content to an extent in the unsaturated polyester-clay composites may be due to the physical binding between matrix and clay particles. The decrease in activation energy after 10 phr clay may be due to cluster formation of clay acting as stress concentrators might have resulted in decrease in thermal stability of the composite.

The plots of kinetic models which were used to evaluate and analyze the kinetic parameters have been shown in Figs. 3-7. The four kinetic models used to understand degradation behaviour shown in Figs. 3, 4, 6 and 7 have yielded near to straight line plots in the range of maximum degradation of the composites.

The kinetic parameters including activation energy values evaluated due to these theories have been shown in Table-1. Friedman plot to find 'n', the order of reaction has 


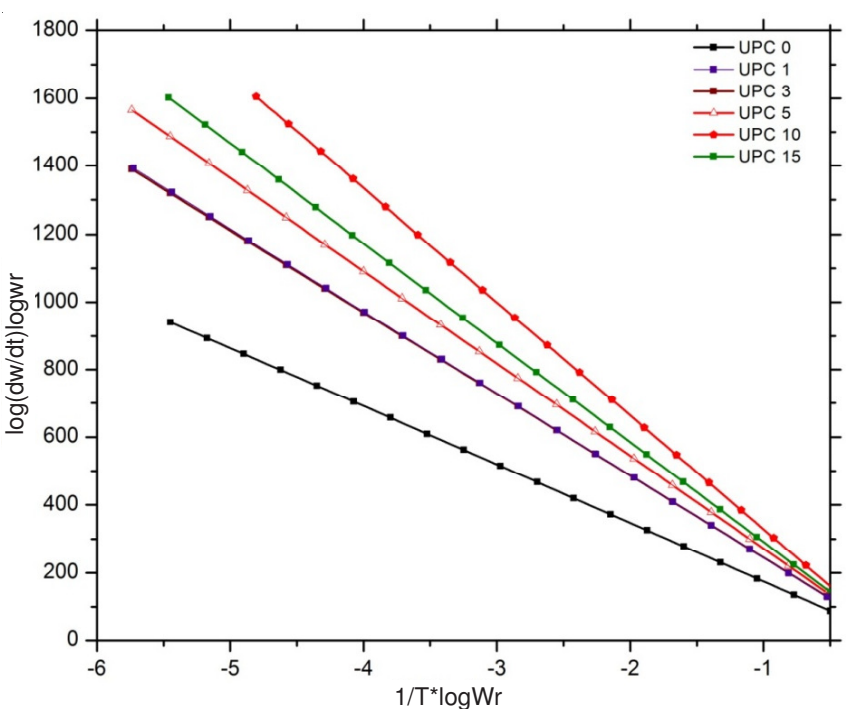

Fig. 3. Freeman-Caroll plot of the degradation kinetic analysis

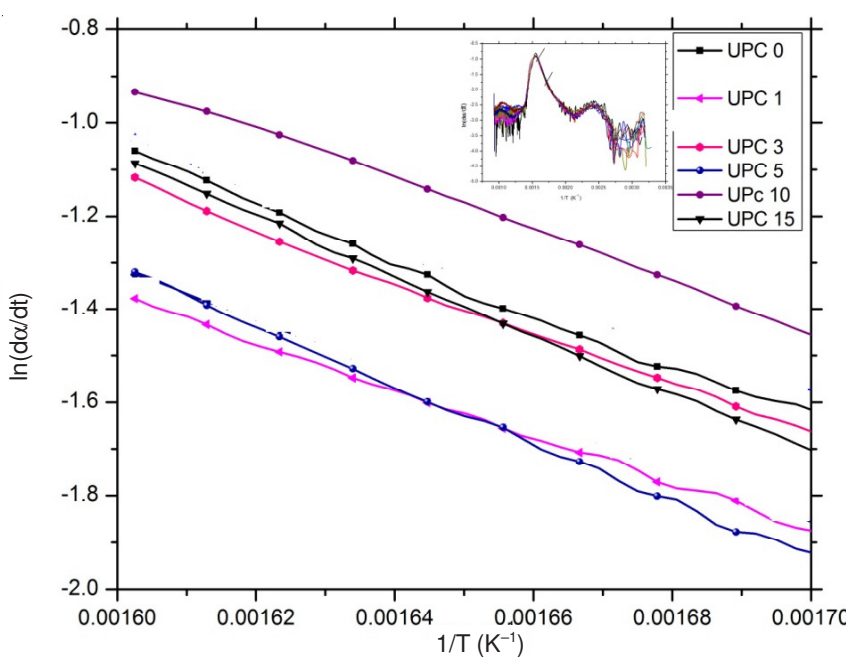

Fig. 4. Friedman plot of the degradation kinetic analysis

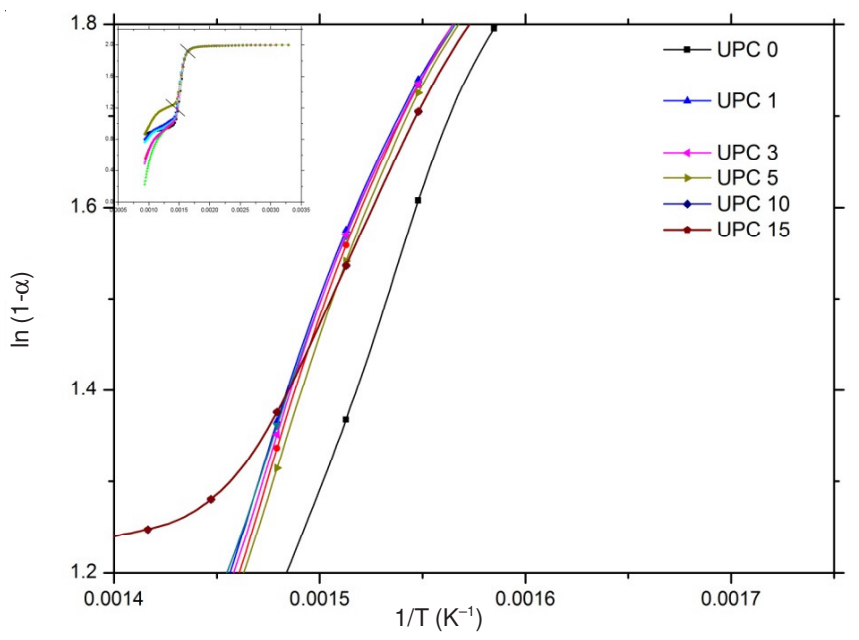

Fig. 5. Friedman plot to find order of reaction ' $n$ '

been shown in Fig. 5. Activation energy values evaluated by Freeman-Caroll method which range from 31.5 to $67.0 \mathrm{~kJ} /$ mol. Horowitz-Metzger method shows the range from 36.11 to $44.05 \mathrm{~kJ} / \mathrm{mol}$ and Sharp -Wentworth Method has yielded activation energy in the range of 71.31-72.30 kJ/mol.

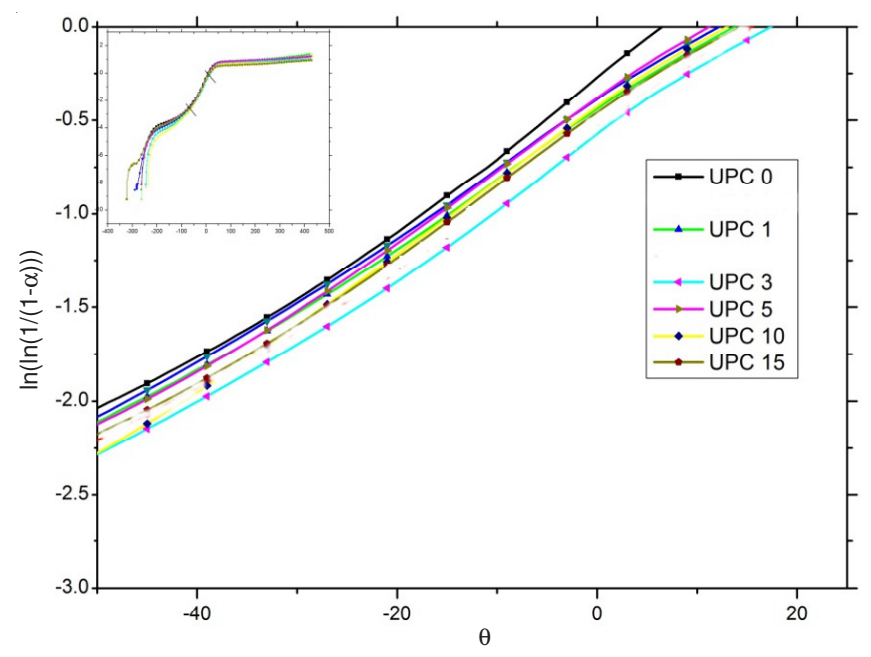

Fig. 6. Horowitz-Metzger plot of the degradation kinetic analysis

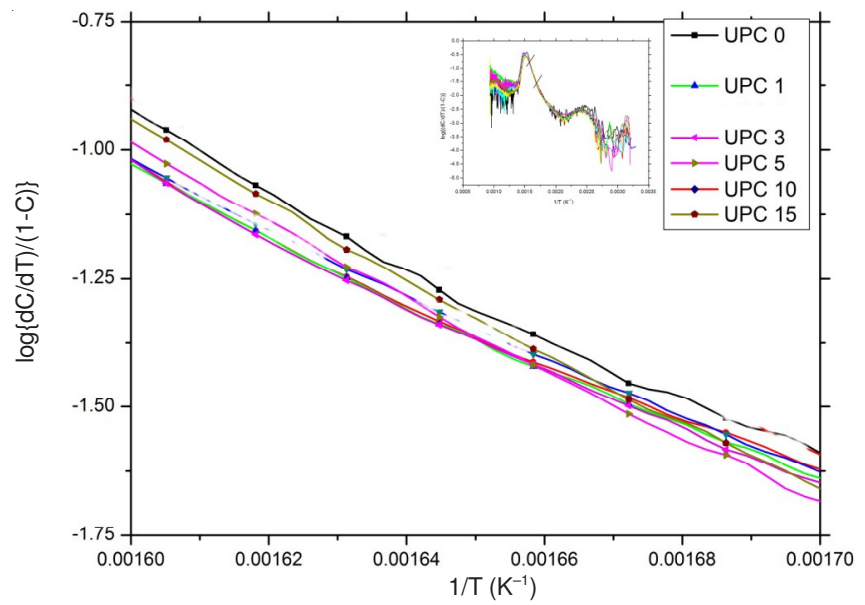

Fig. 7. Sharp-Wentworth plot of the degradation kinetic analysis

Whereas the activation energy evaluated from Friedman method ranges from 41.37 to $50.97 \mathrm{~kJ} / \mathrm{mol}$. All these kinetic theories have shown an increment with the increased clay composition till $10 \mathrm{phr}$. The thermal analysis gives an impression that the thermal stability of unsaturated polyester-clay composites depend on the clay composition to an extent. The slight increase in $\mathrm{T}_{\max }$ from neat UP to clay reinforced UP and activation energy during maximum rate of degradation shows increase in thermal stability to an extent up to $10 \mathrm{phr}$ clay reinforcement and beyond which it has been decreased, showing the optimum load of reinforcement is $10 \mathrm{phr}$. The increase in the activation energy of the unsaturated polyesterclay composites may be due to binding of clay particles in polymer network and, release of volatile fuels and gases during degradation might have acted as a barrier for heat and mass transfer. The order 'n' of the degradation reaction evaluated from Freeman-Caroll and Friedman methods shown in Figs. 3 and 5 found to be greater than 1 but less than 2 and hence the degradation reactions were not of first order.

The results of thermo-mechanical analysis are shown in Fig. 8. The linear thermal expansion $(\alpha)$ region between 75 and $125^{\circ} \mathrm{C}$ (below and just above the glass transition temperature region of isophthalate polyester) is considered for the study. The dimension change was observed to occur linearly 
for all the composites and neat unsaturated polyester. However, the magnitudes of dimension change are found to be high for unsaturated polyester and a drastic decrease is observed upon the reinforcement of clay. The decrease in dimension change for clay reinforced composites is gradual with lower magnitude, because of the difference in the clay composition of the composites. Neat UP sample is having highest dimension change throughout the temperature range. There is drastic reduction in dimension change with just $1 \mathrm{phr}$ clay reinforcement in the temperature range of study. As clay loading increases (up to 5 phr), there is a gradual decrease in dimension change till $100{ }^{\circ} \mathrm{C}$. Beyond $100^{\circ} \mathrm{C}$, the dimension change does not show any regular trend, while it is firmly evident that their values are lying well below than that of neat UP as well as 1 phr clay loaded composite. The decreased dimension changes are due to better adhesion between clay particles and matrix which hinders the expansion of materials and restricts the molecular mobility of the polymer chains ${ }^{18}$.

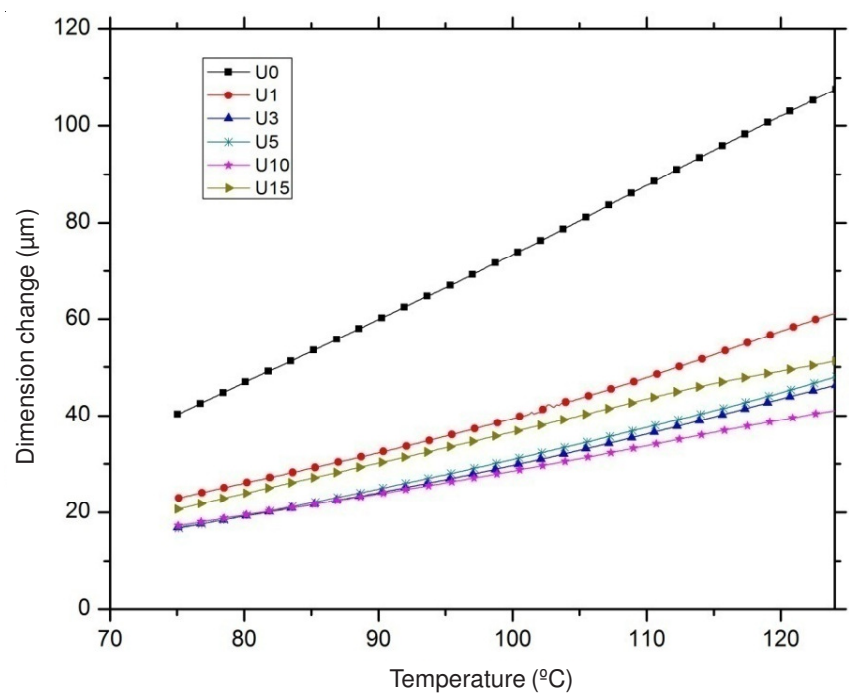

Fig. 8. TMA Plot for all the composite samples and neat unsaturated polyester

The $\alpha$ values were found to decrease with the increase in clay composition with the exception of 1 phr clay. This is an indication that clay particle reinforcement has an effect on the thermal expansion for unsaturated polyester isophthalate matrix. The reduction of a and dimension changes observed after the addition of clay was due to its good dispersion in the polyester and the reduced segmental motion of the polyester matrix $^{18}$. Also better adhesion between clay particles and matrix hinders the expansion of materials. The a in the glassy state is generally related with the molecular chains dilatation and the free volume dilatation ${ }^{19}$. The a values and dimension changes are also tabulated in Table-1.

Fig. 9 shows the effect of clay reinforcement on thermal expansion behaviour of the composites. In this region ( 75 and $125^{\circ} \mathrm{C}$ ) the samples were found to exhibit a decreased expansion upon heating with increased clay reinforcement. However a marginally abnormal increase in a for 1 phr clay loading is observed. The decreased expansion is due to the fine adhesion between filler particles and the polymer matrix. The incorporation of filler restricts the molecular motion of the polymer, hence reduces the material expansion. If the adhesion is poor,

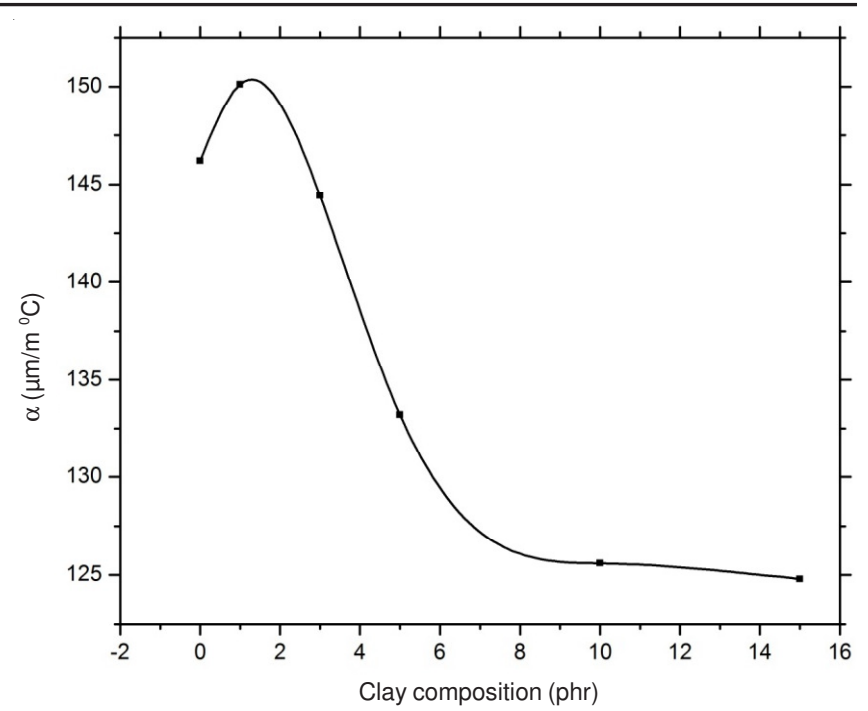

Fig. 9. Effect of clay composition on the thermal expansion co-efficient

the composite will have high thermal expansion with the increasing filler content ${ }^{20}$.

Table- 1 contains the percentage dimensional change for the samples in the same temperature region. The samples were found to exhibit a decreased percentage dimensional variation upon heating with respect to increased clay loading. Similar to $\alpha$, there is an abnormal increase in percentage dimension change for $1 \mathrm{phr}$ clay loading. Generally, in the composites below $\mathrm{T}_{\mathrm{g}}$ the expansion behaviour of both glassy amorphous chains and crystalline chains are quite similar. However, above $\mathrm{T}_{\mathrm{g}}$ the amorphous chains may experience large scale segmental motions and contribute largely to the expansion ${ }^{21}$. Thermomechanical analysis can also be used as a tool in verifying the adhesion between the filler and the matrix.

To know the flame retardant properties of the composites UL-94 Horizontal Burning and Vertical Burning tests were conducted as per the Underwriters Laboratory procedure ${ }^{22}$. Flame retardancy tests with horizontal burning have shown that introduction of clay particles reduces the linear burning rate from $12 \mathrm{~mm} / \mathrm{min}$ for neat unsaturated isophthalate resin to $9 \mathrm{~mm} / \mathrm{min}$ for $0.5 \mathrm{phr}$ clay reinforcement. This has been further reduced up to $4 \mathrm{~mm} / \mathrm{min}$ for $15 \mathrm{phr}$ clay reinforcement. All the samples including neat samples have linear burning rate much below the limiting value of $76 \mathrm{~mm} / \mathrm{min}$. Clay particles contribute to the flame retardancy of the polymeric matrix, producing a refractory oxide residue on the surface of the material and releasing aqueous vapour and carbon dioxide during the decomposition. The endothermic nature of these processes and the dilution of combustible gases of pyrolysis and increase the ignition time and reduce the heat release during the combustion ${ }^{17,18}$, thereby decreasing the burning rate. However UL-94 Vertical Burning tests for these samples showed burning over $30 \mathrm{~s}$ after the removal of flame with dripping which ignited the cotton kept $300 \mathrm{~mm}$ below the sample which is a failure of $\mathrm{V}_{0}, \mathrm{~V}_{1}$ and $\mathrm{V}_{2}$ tests. The results of UL94 tests indicate that the materials can be used for construction and decorative purposes.

Scanning electron microscopy (SEM) analysis has indicated the good dispersion of the clay particles in the matrix which can be seen from Fig. 10b-f. The Fig. 10a corresponds to the 
fractured surface of neat UP resin. SEM of neat UP shows the formation of flake-like structure during the breakage which is often found in UP resins. On the contrary, surfaces of the cured UP resins containing clay particles show that increasing the clay concentration in the UP resin would cause the sample morphology to change from the flake-like to partially flakelike and partially particulate, then to complete particulate structure. The fracture surfaces of UPCs with higher clay content shows numerous micro cracks, which could have been generated at the interface of clay and UP matrix. The flake-like fracture surface of neat UP is due to its brittle nature. The reduction in flake-like structure with the increase in clay content may be due to the reason that, addition of clay reduces brittleness of the UP matrix. The binding between clay particles and matrix seen in the micrograph might have contributed to the increase in $\mathrm{T}_{\max }$ and activation energy.

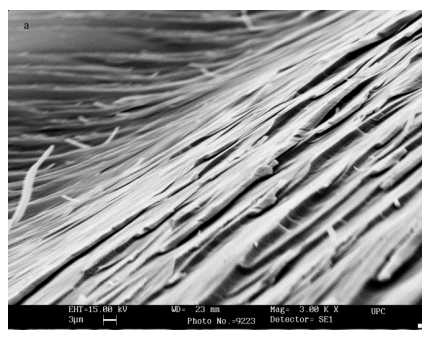

(a)

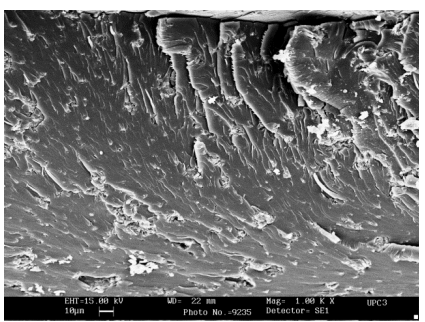

(c)

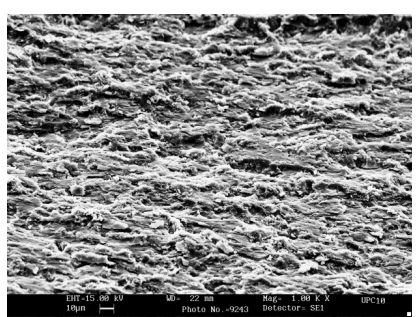

(e)

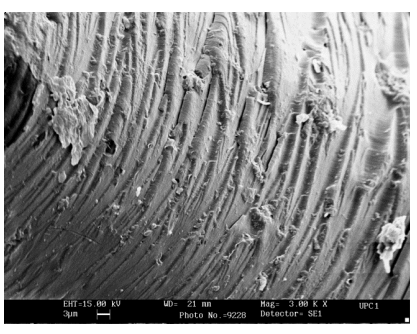

(b)

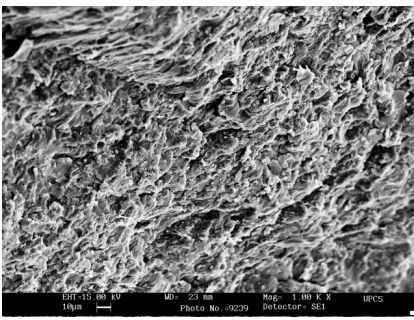

(d)

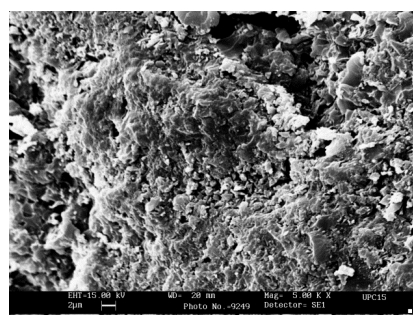

(f)
Fig. 10 (a) SEM of UPC , (b) SEM of UPC1, (c) SEM of UPC3, (d) SEM of UPC5, (e) SEM of UPC10, (f) SEM of UPC15

\section{Conclusions}

Unsaturated polyester resins are one of the most widely used resins for the fabrication of polymer composites because of their competitive cost and ease of processing. With fillers or other additives, UP resins are used in low temperature processes as well as high temperature processes. Addition of a small amount of clay to a polymer matrix has been demonstrated to be an effective method to achieve improvements of mechanical, thermal, barrier and chemical properties and flame retardancy. The FTIR analysis of the prepared unsaturated polyester-clay composites shows no reaction between clay particles and UP matrix. The thermal analysis gives an impression that the thermal stability of unsaturated polyesterclay composites depend on the clay composition. The slight increase in $\mathrm{T}_{\max }$ and activation energy during maximum rate of degradation shows increase in thermal stability to an extent up to UPC 10 and beyond which it has been decreased, showing the optimum load of reinforcement is $10 \mathrm{phr}$. The variation in the activation energy of the unsaturated polyester-clay composites may be due to binding of clay particles in polymer network and, release of volatile fuels and gases during degradation might have acted as a barrier for heat and mass transfer. Freeman-Caroll and Friedman methods have predicted the degradation reactions were not of first order. The composites were observed to exhibit decrease in thermal expansion in the region 75 and $125{ }^{\circ} \mathrm{C}$ upon heating, with increased clay reinforcement. This indicates that the presence of more filler content adds more stability against the thermal expansion of the composites. The UL-94 tests conducted on the composite sample indicate the reduction in burning rate with the increase in clay content and also they indicate that the materials can be used for construction and decorative purposes only. Scanning electron microscopy analysis has indicated the good dispersion of the clay particles in the matrix with the reduction in flakelike structure when clay content was increased, which might be due to reduced brittleness of the UPC matrix.

\section{REFERENCES}

1. A.M. Atta, S.I. Elnagdy and M.E. Abdel-Raouf, J. Polym. Res., 12, 373 (2005)

2. L.Q. Xu and L.J. Lee, Polym. Eng. Sci., 45, 496 (2005).

3. T.M. Wu, S.F. Hsu and J.Y. Wu, J. Polym. Sci. B: Polym. Phys., 41, 560 (2003).

4. D.J. Suh, Y.T. Lim and O.O. Park, Polymer, 41, 8557 (2000).

5. A. Dasari, Z.Z. Yu, Y.W. Mai, G.H. Hu and J. Varlet, Comp. Sci. Technol., 65, 2314 (2005).

6. J.K. Kim, C.G. Hu, S.C. Woo Ricky and M.L. Sham, Comp. Sci. Technol., 65, 805 (2005).

7. C.K. Chozhan, M. Alagar, R.J. Sharmila and P. Gnanasundaram, J. Polym. Res., 14, 319 (2007).

8. X. Fu and S. Qutubuddin, Mater. Lett., 42, 12 (2000).

9. K. Yano, A. Usuki and A. Okada, J. Polym. Sci.: A: Polym. Chem., 35, 2289 (1997).

10. J.C. Matayabas Jr. and S.R. Turner, In ed.: T.J. Pinnavaia, Polymer Clay Nanocomposites, John Wiley, New York, pp. 207-225 (2000).

11. J. Xiao, Y. Hu, Z. Wang, T. Tang, Z. Chen and W. Fan, Eur. Polym. J., 41, 1030 (2005).

12. G. Zhou, S. Movva and L.J. Lee, Polym. Comp., 30, 861 (2009).

13. N.K.A. Al-Sahib and L.S. Yousuf, Proceedings of the SEM Annual Conference, Albuquerque New Mexico, USA, June 1-4 (2009).

14. H.H. Horowitz and G. Metzger, Anal. Chem., 35, 1464 (1963).

15. E.S. Freeman and B. Caroll, J. Phys. Chem., 62, 394 (1958).

16. J.B. Sharp and S.A. Wentworth, Anal. Chem., 41, 2060 (1969).

17. H.L. Freidman, J. Polym. Sci., C6, 183 (1964).

18. T.H. Ho and C.S. Wang, Eur. Polym. J., 37, 267 (2001).

19. K.P. Pramoda, N.T.T. Linh, P.S. Tang, W.C. Tjiu, S.H. Goh and C.B. He, Comp. Sci. Technol., 70, 578 (2010).

20. N. Harish, T. Nagaiah, N. Prabhu and K.T. Varughese, J. Appl. Polym. Sci., 117, 3623 (2010).

21. A.V. Sidorovich, N. Sazanov Yu, O.E. Praslova, N.V. Bobrova, A.V. Novoselova, D.M. Kostycheva and L.A. Nudga, Russ. J. Appl. Chem., 79, 1329 (2006).

22. Underwriters Laboratories Manual, UL-94 Tests for Flammability of Plastic Materials, Northbrook (1982). 